\title{
Study on the Compressive Strength of Hydraulic Cement Mortars About Sand Deposits in Ethiopia
}

\author{
Lidya G. Sime \\ Lanzhou University of Technology, Langongping Road, QiliheDistrict, Lanzhou 730050 China
}

\begin{abstract}
In the field of civil engineering, Silica Sand termed as standard sand has various applications. From manufacturing of glass and glass products to being used as a filter media in water and sewage treatment plants, its use is extremely broad currently. In the construction industry, Silica Sand is used for testing of hydraulic cement, determination of soil density with the sand cone replacement method as well as the production of different construction materials. However, Ethiopia does not manufacture standard sand currently. That is why the country is losing high volume of foreign currency to import this sand from abroad. The purpose of this study is, therefore, to try and locate potential natural sand deposits which satisfies the required quality of standard sand to produce locally. To achieve this objective a desk study is conducted to locate possible standard sand sources, samples from three selected sites from Dire Dawa City, Aleltu River deposit and Alage natural sand deposit were taken. In their natural state, the samples do not satisfy the quality requirements to be used as standard sand. Therefore, the samples are thoroughly washed, oven dried, sieved and separated to various size fractions and mixed in a predetermined proportion to fulfil the grading requirements of the standard sand specification. In all the test results on the processed samples, the compressive and flexural strength of mortar cubes and prisms made with local samples gave lower values compared to the imported standard sand. However, the samples from Dire Dawa and Aleltu show a relatively uniform trend both in the compressive and flexural test results as compared with the imported standard sand. Hence there is a high possibility that these two sand sources can replace the imported standard sand after some processing. The sample from Alage showed some efflorescence, bad quality to consider it as standard sand.
\end{abstract}

(C) 2020 Published by IJRP.ORG. Selection and/or peer-review under responsibility of International Journal of Research Publications (IJRP.ORG) 


\section{INTRODUCTION}

Sand is a naturally occurring loosely packed granular material composed of finely divided rock and mineral particles. It is the most abundant and most consumed mineral, about 15 billion ton per annum ${ }^{[14]}$, Among the different types of sand, Silica Sand is the term used to describe sand that has a remarkably high percentage of Silicon Dioxide $\left(\mathrm{SiO}_{2}\right)$. This type of sand is usually termed and used as Standard Sand. ${ }^{[10]}{ }^{[14]}$ (Simon K., 2014)

Sand and standard sand have vital roles in construction industries. However, the availability of standard sand in the local market is null and more importantly must be imported from abroad. The foreign currency of the country is being dwindled partly because of this. Therefore, in order to improve the foreign currency status of the country as well have readily available standard sand at lower costs, it is important to identify the possible high-quality sand natural deposits of Ethiopia and recommend the necessary improvements or processes required to produce standard sand locally. ${ }^{[7][8]}$

Currently, there are some companies around the world that are selling standard sand by processing their local high-quality sand to fit to the relevant international specifications for standard sand. However, the major portion of the standard sand in use today in Ethiopia is imported from abroad. This has a significant effect in the foreign currency status of the country. In Ethiopia, the major consumers of standard sand are cement factories and construction materials testing laboratories. ${ }^{[6]}[13]$

Around the world, some clean sand (with no or negligible impurities) which demonstrate high resistance to weathering, inertness to chemical reaction, stable under high temperature and pressure fluctuations, also with absence of undesirable air entraining characteristics, low moisture content, which meet specific gradation requirement and also showing consistent behaviours and characteristics when used together with different materials or in different circumstances are labelled as standard sand. Standard sand is used for different purposes around the world such as; as an input for testing of hydraulic cement in the laboratory works of construction industry and cement manufacturing plants, and soil and pavement materials' density determination by the sand-cone replacement method in roads, dams and other embankment and pavement construction projects. ${ }^{[1]}[5]$

One of the sands used as standard sand is Ottawa sand. Ottawa sand is found naturally along the Ottawa River and after some processing, it is made to satisfy all the technical specifications required to be used as a standard sand. One of the standard testing protocols is ASTM. ASTM-Test-Sands are specially graded sands for ASTM tests. The naturally rounded silica sands of nearly pure quartz are mined from the Ottawa, Illinois area is used as ASTM test sand after screening to fit the test sand gradation curve. Two different gradings are set in ASTM, each designed for a specific type of test. The 20-30 standard sand for density of soils testing in the sand cone replacement test method and the Graded Sand for testing of hydraulic cement. ${ }^{[2]}{ }^{[16]}$

Table 1.Standard Sand characteristics and grading. ${ }^{[2]}$

\begin{tabular}{|c|c|c|}
\hline Characteristics & 20-30 sand & Graded sand \\
\hline \multicolumn{3}{|c|}{ Grading, Percent passing sieve } \\
\hline $1.18 \mathrm{~mm}(\# 16)$ & 100 & 100 \\
\hline $850 \mu \mathrm{m}(\# 20)$ & 85 to 100 & \\
\hline $600 \mu \mathrm{m}(\# 30)$ & 0 to 5 & 96 to 100 \\
\hline $425 \mu \mathrm{m}(\# 40)$ & - & 60 to 75 \\
\hline $300 \mu \mathrm{m}(\# 50)$ & - & 16 to 30 \\
\hline $150 \mu \mathrm{m}(\# 100)$ & - & 0 to 4 \\
\hline
\end{tabular}




\begin{tabular}{|l|l|l|}
\hline $\begin{array}{l}\text { Difference in air content of } \\
\text { mortars made with washed and } \\
\text { unwashed sand; max \% air }\end{array}$ & 2.0 & 1.5 \\
\hline Source of sand & $\begin{array}{l}\text { Ottawa, IL or LeSuer, } \\
\text { MN }\end{array}$ & Ottawa, IL \\
\hline
\end{tabular}

In the above specification table source of sand is specifically specified after confirming that such source consistently satisfies the other, not specified in the above table, quality parameters needed to function as standard sand. ${ }^{[2]}$

Hence, we need to prove the attainment of these all criteria in the local natural sand sources or after some processing to accept our Ethiopian source as a standard testing sand to ASTM or other similar international testing procedures. ${ }^{[2]}$

In the case of Mugher Cement Factory, the factory consumes a total of 40kgs of imported standard sand per day. Presently, standard sand is being sold for $\$ 10$ per $\mathrm{kg}$. Then this factory spends a total of $\$ 400$ a day, resulting in an annual expense of $\$ 146,000$. It can clearly be seen that there are great benefits to produce standard sand using locally available natural sand considering the fact that the country will need more standard sand as there are many huge construction projects ongoing and coming and more cement factories are expected to be constructed in the near future which would require above $\$ 3$ million to import standard sand otherwise . Recent observations of the construction boom can be taken as concrete evidence. ${ }^{[8]}[12]$

Standard sand, a higher quality sand, which is graded according to a specified standard is normally used for testing of cement in mortar and concrete. Therefore, the main purpose of this research is an attempt to produce Standard Sand using locally available natural sand deposits and totally substitute the imported standard sand. This research will make standard sand readily available to the market avoiding the extended waiting time because of the importing process and make the laboratory tests of the construction industry and cement plants less costly and efficient. Finally, it is highly believed that the outcome of this research will create additional jobs and income to citizens since it opens up a new and different working platform in the construction sector. ${ }^{[5]}$

\section{RESEARCH METHODOLOGY}

The methodology implemented in this research is a literature review followed by different laboratory tests and analysis. Some of the tests are gradation, impurities (clay) content, compressive and flexural strength of mortar prisms. The required characteristics (quality) of the standard sand, specific to testing hydraulic cement, are identified. Local sand sources that could satisfy the relevant international standard sand specification or exhibit similar attributes with the imported standard sand are identified and tested in accordance with CEN relevant specific testing procedures. the deviation in results from the imported standard sand is noted. The impact of these deviations on the expected lab test results, as controlled by the imported standard sand, are studied and remedial measures or processes on the proposed natural sand samples are carried out. The improved sand samples again are tested to confirm the attainment of the specification set by the same material testing standard. Though the processed sand could not fulfil some of the specifications, the trend of using two of the sands as a standard sand is proved to be consistent with some proportionate difference in result, and hence the sources with the recommended improvement in quality could be used as a standard sand with some adjustment factors. ${ }^{[2][3]}$

Potential sources of standard sand are studied among those sand sources which are actively being utilized as a regular sand for construction purposes in different parts of the country. Sand sources which could deliver large volume of sand with higher quality attributes are considered as potential standard sand sources.

Due to economic, mobility and time constraints three active sand sources with high utilization records are selected for further investigation. Then, adequate quantity of samples is collected from these selected sand sources. Test specimens prepared, impurities (clay) content determined, washed, screened to separate grain 
sizes, and mixed in a definite predetermined proportion to meet the standard sand gradation specification. Then mortar cubes and prisms samples were casted using the processed sand samples and the compressive and flexural strengths are determined to assess the suitability of the sand sources to be used as a standard sand. The sand samples for laboratory investigation were collected from Dechatu River in Dire Dawa City, Aleltu Site (which is near the Abay Basin) and Alage Sites (near the town of Bulbula). ${ }^{[3][4][8]}$

\section{RESULTS}

The following table shows the results of impurities (clay) content test conducted on the three samples.

Table 2. Clay Content for Dire Dawa Sample

\begin{tabular}{|l|l|l|c|}
\hline $\begin{array}{c}\text { Item No. of } \\
\text { Sample }\end{array}$ & \multicolumn{1}{|c|}{$\begin{array}{c}\text { Mass of sand before } \\
\text { washing (gm) }\end{array}$} & $\begin{array}{c}\text { Mass of sand after washing } \\
(\text { retained on sieve \#200) }(\mathbf{g m})\end{array}$ & $\begin{array}{c}\text { Clay Content } \\
(\boldsymbol{\%})\end{array}$ \\
\hline Sample 1 & 500.00 & 483.50 & $3.30 \%$ \\
\hline Sample 2 & 500.00 & 489.22 & $2.16 \%$ \\
\hline Sample 3 & 500.00 & 485.20 & $2.96 \%$ \\
\hline \multicolumn{2}{|r}{} & Average Clay Content & $\mathbf{2 . 8 1 \%}$ \\
\hline
\end{tabular}

Table 3. Clay Content for Aleltu Sample

\begin{tabular}{|l|l|l|c|}
\hline $\begin{array}{c}\text { Item No. of } \\
\text { Sample }\end{array}$ & $\begin{array}{c}\text { Mass of sand before } \\
\text { washing }(\mathbf{g m})\end{array}$ & $\begin{array}{c}\text { Mass of sand after washing } \\
\text { (retained on sieve \#200) }(\mathbf{g m})\end{array}$ & $\begin{array}{c}\text { Clay Content } \\
(\boldsymbol{\%})\end{array}$ \\
\hline Sample 1 & 500.00 & 472.70 & $5.46 \%$ \\
\hline Sample 2 & 500.00 & 469.20 & $6.16 \%$ \\
\hline Sample 3 & 500.00 & 463.20 & $7.36 \%$ \\
\hline \multicolumn{2}{|r}{} & Average Clay Content & $\mathbf{6 . 3 3 \%}$ \\
\hline
\end{tabular}

Table 4. Clay Content for Alage Sample

\begin{tabular}{|l|l|l|l|}
\hline $\begin{array}{c}\text { Item No. of } \\
\text { Sample }\end{array}$ & $\begin{array}{c}\text { Mass of sand before } \\
\text { washing }(\mathbf{g m})\end{array}$ & $\begin{array}{c}\text { Mass of sand after washing } \\
\text { (retained on sieve \#200) }(\mathbf{g m})\end{array}$ & $\begin{array}{c}\text { Clay Content } \\
(\boldsymbol{\%})\end{array}$ \\
\hline Sample 1 & 500.00 & 495.10 & $0.98 \%$ \\
\hline Sample 2 & 500.00 & 492.64 & $1.47 \%$ \\
\hline Sample 3 & 500.00 & 496.83 & $0.63 \%$ \\
\hline \multicolumn{2}{|r|}{ Average Clay Content } \\
\hline
\end{tabular}




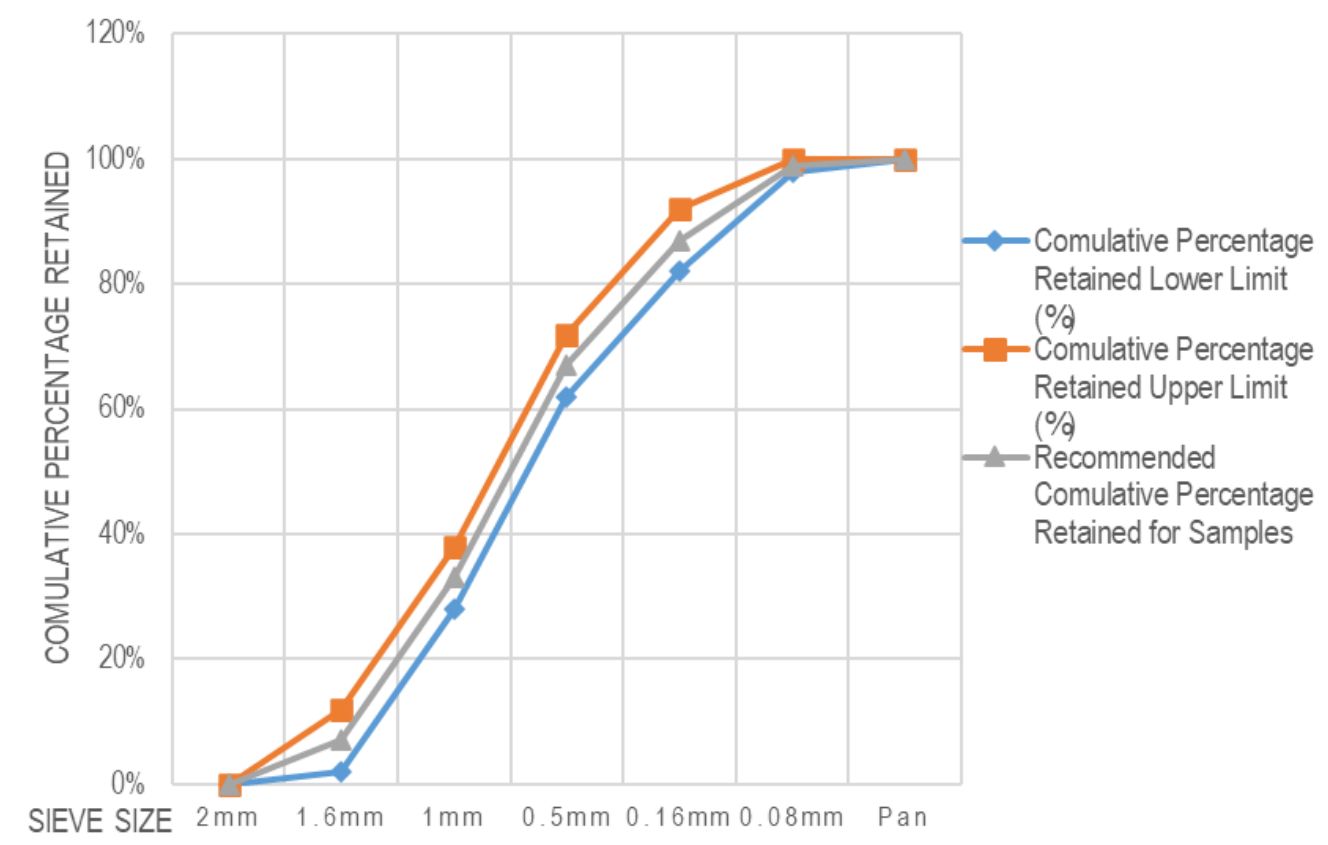

Figure 2. a sieve analysis of cumulative percentage retained retained/ ${ }^{[2]}$

\section{Compressive Strength}

Table 5. Summary of Test Results for 2 days test ages

\begin{tabular}{|l|c|c|}
\hline Sample Location/Type & $\begin{array}{c}\text { Compressive } \\
\text { Strength (MPa) }\end{array}$ & $\begin{array}{c}\text { Percentage Deviation from the } \\
\text { Standard Sand (\%) }\end{array}$ \\
\hline Dire Dawa Sample & 18.00 & $91.8 \%$ \\
\hline Aleltu Sample & 14.80 & $75.5 \%$ \\
\hline Alage Sample & 5.70 & $29.1 \%$ \\
\hline CEN Standard Sand & 19.60 & $100.0 \%$ \\
\hline
\end{tabular}

Table 6. Summary of Test Results for 7 days test ages

\begin{tabular}{|l|r|r|}
\hline Sample Location/Type & $\begin{array}{c}\text { Compressive } \\
\text { Strength (MPa) }\end{array}$ & $\begin{array}{c}\text { Percentage Deviation from the } \\
\text { Standard Sand (\%) }\end{array}$ \\
\hline Dire Dawa Sample & 29.98 & $79.3 \%$ \\
\hline Aleltu Sample & 25.60 & $67.7 \%$ \\
\hline Alage Sample & 8.30 & $22.0 \%$ \\
\hline CEN Standard Sand & 37.80 & $100.0 \%$ \\
\hline
\end{tabular}

In all of the test results, the compressive strength of mortar cubes made with local samples gave lower results. However, a relatively uniform trend was observed in the compressive test result between the local samples 
and the imported sand. In the case of the Alage sample, the mortar was of observed to be of poor-quality. The fresh mortar did not look homogeneous, looking very porous and exhibiting efflorescence. Additionally, after storing the prism in the pond, the sample had organic materials growing on it after 7 days. This indicates that the sample has excess organic materials embedded within itself.

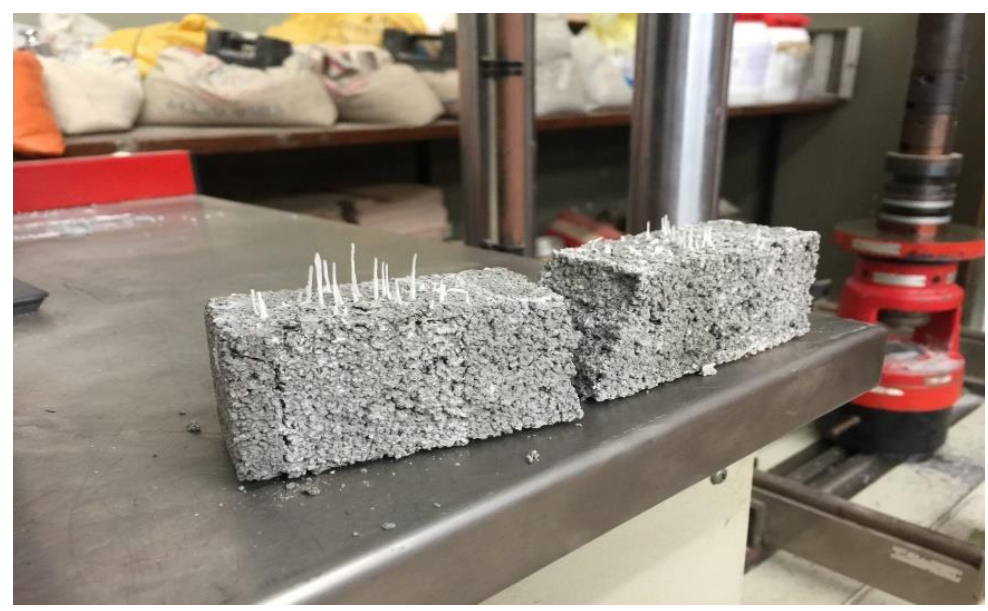

Figure 3. Alage sample after the 7th day ponding exposing efflorescence

Based on the seventh day compressive strength values, a mathematical relationship is established for the two samples (i.e. Dire Dawa and Aleltu Sample). The following tabulated results are used to develop the mathematical relationship. Consequently, the compressive strength is stated as $y=-15 x^{2}+545.5 x-4939.3$ (E.q. 6.1) for Dire Dawa sample and $y=0.8571 x^{2}-23.714 x+182.75$ (E.q. 6.2) for Aleltu sample where $x$ is the compressive strength value obtained by local sample and $y$ is its corresponding CEN value. ${ }^{[7]}$

Table 7. Summary of compressive strength for each individual prism for Dire Dawa ample

\begin{tabular}{|c|c|c|c|}
\hline \multirow{2}{*}{ Prism No. } & \multicolumn{3}{|c|}{ Compressive Strength (Mpa) } \\
\cline { 2 - 4 } & $\begin{array}{c}\text { Dire Dawa } \\
\text { Sample }\end{array}$ & $\begin{array}{c}\text { CEN } \\
\text { Standard } \\
\text { Sand }\end{array}$ & $\begin{array}{c}\text { Percentage Deviation from the } \\
\text { Standard Sand (\%) }\end{array}$ \\
\hline Prism 1 & 17.90 & 19.00 & $94.21 \%$ \\
\hline Prism 2 & 18.00 & 19.70 & $91.37 \%$ \\
\hline Prism 3 & 18.10 & 20.10 & $90.05 \%$ \\
\hline Average Result & $\mathbf{1 8 . 0 0}$ & $\mathbf{1 9 . 6 0}$ & $\mathbf{9 1 . 8 4 \%}$ \\
\hline
\end{tabular}




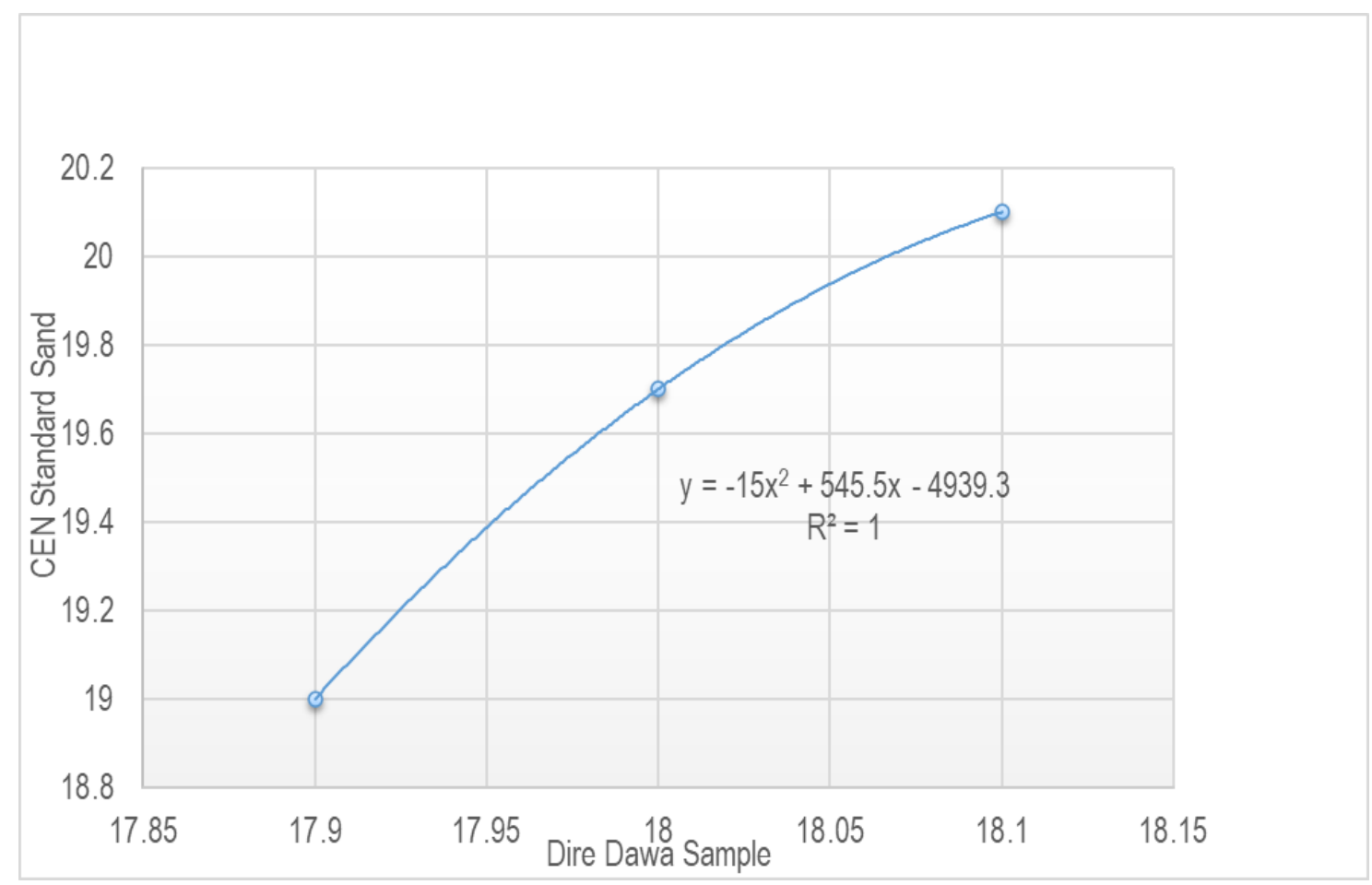

Figure 4. A plot of compressive strength test results obtained using Dire Dawa sample and CEN sand

Table 4. Summary of compressive strength for each individual prism for Aleltu sample

\begin{tabular}{|c|c|c|c|}
\hline \multirow{2}{*}{ Prism No. } & \multicolumn{3}{|c|}{$\begin{array}{c}\text { Compressive Strength } \\
\text { (MPa) }\end{array}$} \\
\cline { 2 - 4 } & $\begin{array}{c}\text { Aleltu } \\
\text { Sample }\end{array}$ & $\begin{array}{c}\text { CEN } \\
\text { Standard } \\
\text { Sand }\end{array}$ & $\begin{array}{c}\text { Percentage Deviation from the } \\
\text { Standard Sand (\%) }\end{array}$ \\
\hline Prism 1 & 14.40 & 19.00 & $75.79 \%$ \\
\hline Prism 2 & 14.90 & 19.70 & $75.63 \%$ \\
\hline Prism 3 & 15.10 & 20.10 & $75.12 \%$ \\
\hline Average Result & $\mathbf{1 4 . 8 0}$ & $\mathbf{1 9 . 6 0}$ & $\mathbf{7 5 . 5 1 \%}$ \\
\hline
\end{tabular}




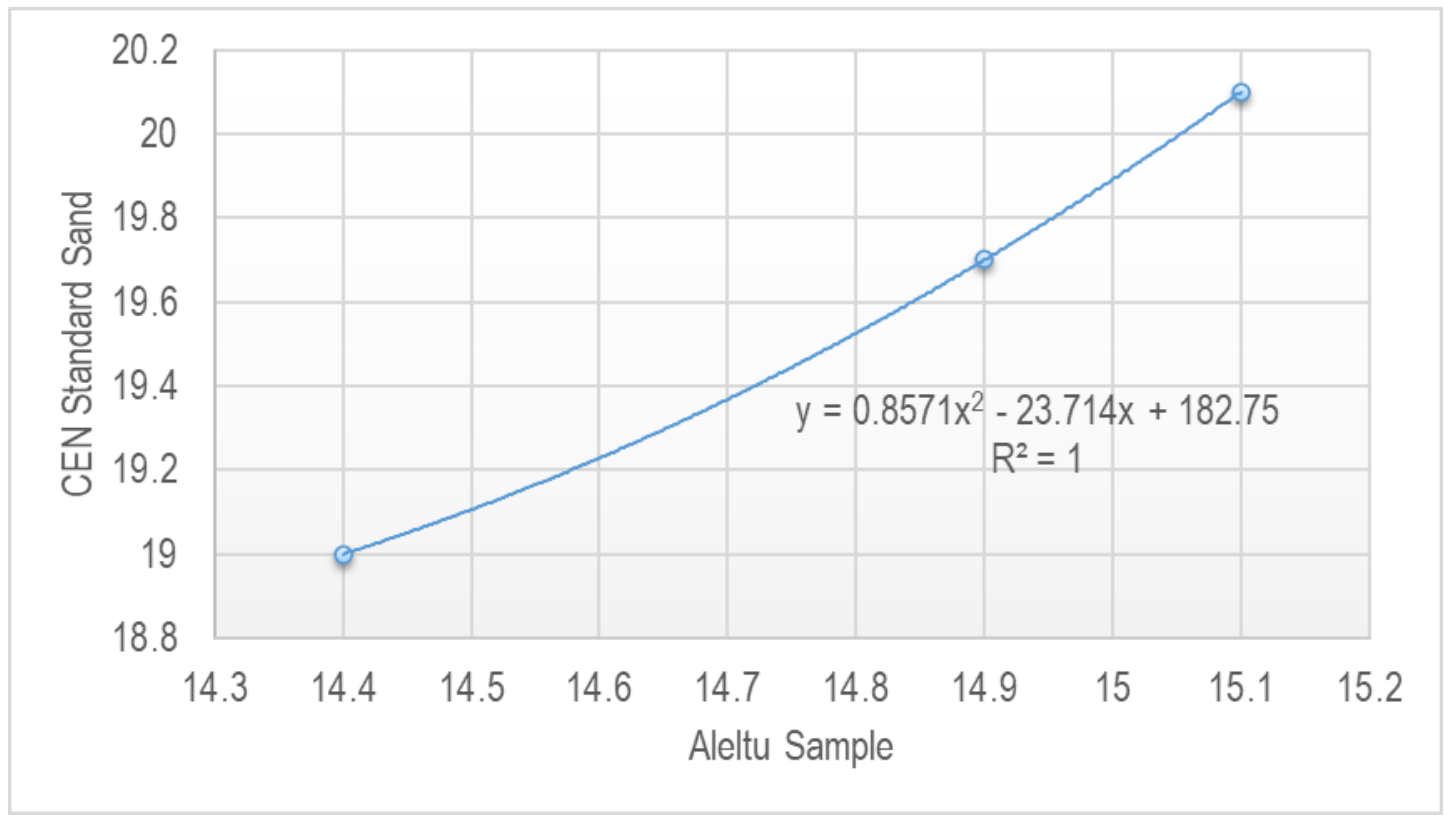

Figure 4.2: A plot of compressive strength test results obtained using Aleltu and CEN sand ${ }^{[2]}$

\section{PREPARATION OF PROPOSED ETHIOPIAN STANDARD SAND}

\section{CHOICE OF SAND TYPE}

Even though Ethiopia has large number of sand deposits throughout the country, only three locations have been thoroughly investigated in this research, namely Dire Dawa, Alage and Aleltu. The analysis from the previous chapters suggested that the sample acquired from Alage was not advisable. The results that yielded from the tests was extremely below of what was expected. Additionally, during the ponding stage, the mortar cube showed signs of presence of efflorescence. Therefore, the sample was rejected from this research. ${ }^{[3][4]}$

Consequently, the samples that are possible replacement of CEN Standard Sand, that will be used for testing are found at Dire Dawa or Alage. However, from the test results, samples that were taken from Dire Dawa yielded the most comparable result. This does not mean that the sample taken from Aleltu was inadequate but rather slightly inferior to the Dire Dawa Sample. ${ }^{[3][4]}$

\section{PREPARATION OF SAND SAMPLE}

As previously stated, samples were taken at random and in bulk. The collected samples are thoroughly washed in a large sink until clear water is seen when mixing. The washing of the sands is done to remove any debris matter that may be found in the sand. However, the main reason the samples must be washed is to reduce or eliminate the impurities content of sand to get it to the desired level. The amount and duration of washing will depend on the level of impurities in the natural sand deposit. ${ }^{[17]}$

Following the washing process, the sand sample should be oven dried. The oven drying step should be for at least 24 hours in order the remove any excess moisture that may be found in the sand. Then the samples will be sieved into their respective factions so that the blending process will be simplified. It is highly recommended that the sand be separated into their respective factions and carefully stored in separate containers. Therefore, we blend the sand to fulfil the grading requirements as put forth by CEN. The blending requirements for the proposed Ethiopian Standard Sand is presented in the following table. Please note that this blending requirement was applied for all samples used in this research. ${ }^{[15][17]}$ 
Table 5. Blending proportions of separate sizes of local sand samples to meet standard sand specification

\begin{tabular}{|l|l|}
\hline Sieve Size & $\begin{array}{l}\text { Mass Retained on Each Sieve } \\
(\mathbf{g m})\end{array}$ \\
\hline $2.0 \mathrm{~mm}$ & 94.50 \\
\hline $1.18 \mathrm{~mm}$ & 351.00 \\
\hline $425 \mu \mathrm{m}$ & 459.00 \\
\hline $150 \mu \mathrm{m}$ & 270.00 \\
\hline $75 \mu \mathrm{m}$ & 162.00 \\
\hline Pan & 13.50 \\
\hline
\end{tabular}

\section{PROPOSED CONVERSION FACTOR}

After conducting tests of local samples, the results showed that the local samples gave a lower result compared to CEN Standard Sand. However, the results seem to be uniform and one can deduce a relationship between the CEN and local sand. Finally, the following conversion factors should be adapted whenever local samples are substituted for CEN Standard Sand. ${ }^{[2][16]}$

Whenever using Dire Dawa sand as standard sand, the equation $y=-15 x^{2}+545.5 x-4939.3$. The "y" value will give the equivalent value if CEN Standard Sand would have been used. Consequently, whenever sand from Aleltu is used as standard sand, the equation $y=0.8571 x^{2}-23.714 x+182.75$ as a conversion factor to get the actual result. ${ }^{[7]}$

\section{FUTURE SCOPES}

Factors like urbanization and growth of a country increases the requirement for sand as infrastructure and building plans largely requires extensive supply. ${ }^{[9]}$ (Ioannidou, D. et al. 2020). Particularly Developing countries depend on imported sand via sand trade to meet their demand, for instance, by 2018, Singapore was one of the world's highest sand importer importing an estimate of $\$ 366$ million worth of sand. ${ }^{[11]}$ (Kyger, L. 2019). Such sand trades can cause both environmental concerns in an exporting countries and high quantity expenditure of foreign currency in an importing country. ${ }^{[11]}$ (Kyger, L. 2019). On the other hand, making more accurate investigation and estimation of sand extractions and production signifies an advantage of a sand as a commodity that can create supplies and benefits in areas that are in need of it and generates value to the sites producing it. ${ }^{[12]}$ (Lamb, V. et al. 2019). For example, sand extraction from areas of Cambodia is an implicatory of sand extraction being used as a commodity for Singapore's expanding demand for sand associated with its growth and development there by creating a trade link between the two countries. ${ }^{[12]}$ (Lamb, V. et al. 2019). Therefore, purposeful study of locating local natural sand deposits can significantly meet the high demands of one side while benefits can considerably arise in the other side.

\section{CONCLUSIONS AND RECOMMENDATIONS}

\section{CONCLUSIONS}

The major goal of this research, as it was mentioned in the objective section of this paper, is to prepare a standard testing sand through selective sampling and testing of local sand sources, which could in turn be used as Ethiopian standard sand that would replace imported sand which is used mainly for testing of hydraulic cement purpose which could automatically also be used as testing sand in the sand cone replacement method of soil density by only screening the local standard sand with sieves \#20 and \#30. 
Based on the grain size analysis and physical tests, the samples in their natural state are not in accordance with the requirements set by CEN. Therefore, in order for these sand samples to be used as Ethiopian standard sand, they have had to undergo washing, drying, screening into their individual size fractions and finally blending them to fit the gradation standards set by CEN.

The comparison test made between the local and imported sand in compression showed that there is a uniform trend between the two sample and additional relationships can be developed. This correlation can be defined through Equations 6.1\&6.2 for the Dire Dawa and Aleltu sample respectively. Hence, one can convert the compressive test results obtained using the local sand to it CEN equivalent value by using these equations.

\section{RECOMMENDATIONS}

This research has attempted to prepare Ethiopian standard sand by taking local sand samples. However, due to financial constraints and time limitations, this research could not cover all the detail laboratory investigation on the behaviour of local sand. In view of this, it would desirable to consider the following recommendations and comments to obtain a better result.

1. Even though the country is endowed with abundant sand deposits due to financial limitations and time constraints sand samples taken from three different sites to be investigated. A better result would be obtained by taking additional sand samples from several other sites.

2. Due to the high cost of laboratory testing and imported CEN sand, only 6 prisms from each site was casted and compressive strength results compared. A better result would have been yielded if additional prisms were casted.

3. Even though the Alage sample was discarded to be used as Ethiopian standard sand, it can be seen that the sand contains high amount of Silica.

\section{References}

1. AASHTO T-191, 1974, Standard specification for transportation materials and methods of sampling and testing. $11^{\text {th }}$ Ed, Washington

2. ASTM 2000, Annual Book of ASTM Standards, Washington D.C.

3. Bruni, M. (2012). Rapid Sand Filtration. Retrieved from http://www.sswm.info/

4. Bruni, M. (2012). Slow Sand Filtration. Retrieved from http://www.sswm.info/

5. BS EN 196-1, 1995, Methods of Test for Soils for Civil Engineering Purposes, British Standards Institution, London.

6. Evaluation of Sheet Glass Raw Materials (Silica Sand, Dolomite and Calcite Marble, Feldspar at North Shoa, West Haraghe and Sidamo; Geological Survey, Ministry of Mines \& Energy, 1989).

7. Grayson, Ames (2012, June 29). Basic Civil Engineering - Chapter Two Sand. Retrieved from https://www.safaribooksonline.com/library/view/Basic+Civil+Engineering/9788131729885/xhtml/chapter002.xhtml\#img$\underline{13 \_1}$

8. International Journal of Emerging Technology and Advanced Engineering: Foundry Properties of Silica Sand Deposits at Blue Nile Gorge and Jemma River Basin in North-western Ethiopia (Volume 4, Issue 4, April 2014)

9. Ioannidou, D., Sonnemann, G., \& Suh, S. (2020, April 07). Do we have enough natural sand for low-carbon infrastructure? Retrieved September 20, 2020, from https://onlinelibrary.wiley.com/doi/full/10.1111/jiec.13004?casa_token=Scp14Mkwt_EAAAAA\%3AVFBsuVfvjmrKeiDb5up QyWNP4Hsj8QX11a4jG1ayYmMzCe06hPS5EXemysit9Em6XxfJDZLT5coUAn8- 
10. Joseph Castro (2013, May 28). What is Sand? Retrieved from http://www.livescience.com/34748-what-is-sand-beach$\underline{\text { sand.html }}$

11. Kyger, L. (2019, September 10). WAVE OF GLOBAL SAND TRADE MAY BE DEPLETING BEACHES. Retrieved September 19, 2020, from https://www.globaltrademag.com/wave-of-global-sand-trade-may-be-depleting-beaches/

12. Lamb, V., Marschke, M., \& Rigg, J. (2019). Trading Sand, Undermining Lives: Omitted Livelihoods in the Global Trade in Sand. Retrieved September 20, 2020, from https://www.tandfonline.com/doi/full/10.1080/24694452.2018.1541401?casa token=KwivYsfI3g0AAAAA\%3ApI9HbXklPs 5O7XUGWqsXm_A41AeEgpoaEI9UfG9OU4pwZjp0ZB3ZBMB_pFUVuIH_llpeg7fm6JaI7w

13. Preparation of Ethiopian Standard Sand for the Purpose of Construction and Testing, Partial fulfilments of the requirements of the Degree of Master of Science in Geotechniques at Addis Ababa University (September 2005)

14. Simon, Keith (2014, January 9). What is Silica Sand? Retrieved from http://www.wisegeek.org/what-is-silica-sand.htm

15. "Slow Sand Filtration" (PDF). National Drinking Water Clearinghouse. Retrieved from http://www.nesc.wvu.edu/pdf/dw/publications/ontap/2009 tb/slow_sand filtration_dwfsom40.pdf

16. Tentative Specification for Standard Sand, ASTM C778-748

17. UNEP Global Environmental Alert Service - Sand, rarer than one thinks (2014) 